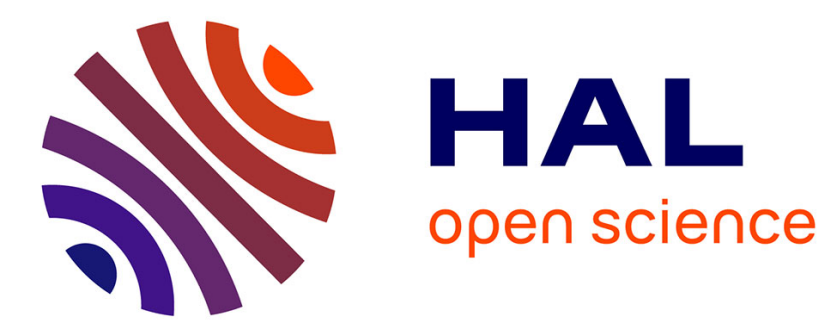

\title{
Risk-based strategies for wind/pumped-hydro coordination under electricity markets
}

Franck Bourry, Luis Costa, Georges Kariniotakis

\section{To cite this version:}

Franck Bourry, Luis Costa, Georges Kariniotakis. Risk-based strategies for wind/pumped-hydro coordination under electricity markets. Bucharest PowerTech Conference, Jun 2009, Bucharest, Romania. pp.3086-3093 - ISBN 978-1-4244-2234-0, 10.1109/PTC.2009.5282276 . hal-00505139

\section{HAL Id: hal-00505139}

https://hal-mines-paristech.archives-ouvertes.fr/hal-00505139

Submitted on 29 Dec 2010

HAL is a multi-disciplinary open access archive for the deposit and dissemination of scientific research documents, whether they are published or not. The documents may come from teaching and research institutions in France or abroad, or from public or private research centers.
L'archive ouverte pluridisciplinaire $\mathbf{H A L}$, est destinée au dépôt et à la diffusion de documents scientifiques de niveau recherche, publiés ou non, émanant des établissements d'enseignement et de recherche français ou étrangers, des laboratoires publics ou privés. 


\title{
Risk-Based Strategies for Wind/Pumped-Hydro Coordination under Electricity Markets
}

\author{
Franck Bourry, Luís M. Costa, Member, IEEE, and George Kariniotakis, Member, IEEE
}

\begin{abstract}
When participating in an electricity market, wind power generation may be penalized by increased regulation costs due the stochastic nature of the wind resource. The negative impact associated to the stochastic nature of wind may be reduced by coupling the wind farm with energy storage facilities, thus constituting a virtual power plant. In this paper, focus is put on advanced methods for reducing regulation costs. A novel method is proposed for the intra-day scheduling and operation of such a plant in an electricity market environment. Such method is able to minimize the imbalance penalty risks associated to wind power forecast uncertainty through a rolling-window approach. Results based on a real-world test case are presented and discussed.
\end{abstract}

Index Terms-Decision-Making, Risk, Virtual Power Plant Operation, Wind Power, Pumped-Hydro, Electricity Markets, Wind Power Forecasting.

\section{INTRODUCTION}

I NCREASING environmental and security of supply concerns as well as technological advances compose a favorable environment for the deployment of generators based on renewable energy sources (RES). However, the operation of RES units such as wind or solar plants presents the inconvenience of being intrinsically dependent on the variability of the wind or solar resource. This makes large scale integration of renewable units into power systems particularly challenging.

Due to the unbundling process in several countries, renewable energy generators will often operate under electricity market conditions. However, electricity markets have been originally designed to integrate power producers having the possibility to control their individual power production at all times, which is not the case of power producers using non-dispatchable RES units (e.g.: wind or solar plants). As a consequence, RES power producers may consequently be penalized by electricity market rules [1].

Under an electricity market participation framework, power producers may place bids in several types of markets, such as day-ahead or intra-day electricity markets. For participating in short-term markets, power producers must make market bidding decisions about the amount of energy to contract and at which price to contract it. The market bidding decision has to be made a given amount of time prior to the actual delivery with imperfect knowledge about what the actual future power generation will be. At the delivery time, any existing differences between contracted and produced energy

Franck Bourry and George Kariniotakis are with MINES ParisTech, CEP - Center for Energy and Processes, CNRS FRE 2861, BP 2071 rue Claude Daunesse 06904 Sophia Antipolis Cedex, France. Luís M. Costa was also with MINES ParisTech, CEP and is currently with Areva T\&D, Lyon, France.

e-mail contacts: franck.bourry@mines-paristech.fr, georges.kariniotakis@mines-paristech.fr may occur, constituting energy imbalances. Such imbalances may be penalized a posteriori by balancing markets, which are also commonly named real-time markets, or regulating markets [2].

For placing bids in the market, power producers relying on non-dispatchable renewable energy sources must use some kind of forecasts of the amount of energy that will be produced during a given future period of time. However, the stochastic nature of their production results to some forecast uncertainty. This uncertainty is at the origin of the energy imbalances described in the previous paragraph.

Some research efforts have been made in the past on methodologies for reducing the imbalance costs paid by renewables participating in electricity markets [3] [4] [5] [6]. These studies consider a direct participation of wind farms in the electricity market. However, in a more general case, virtual power plants composed by some combination of renewable energy sources with conventional units and, eventually, energy storage devices could be considered. Examples of such types of combinations can be found in [7] [8] [9].

The main objective of this work is to propose a method for managing a virtual power plant under electricity market conditions, where focus is put on the minimization of imbalance penalties. The considered virtual power plant consists of a wind farm coupled with an energy storage device. The advantages that might be obtained from the application of an advanced intra-day scheduling of the virtual power plant are evaluated. This is done by performing a rolling-window approach for dispatching the energy storage device with the objective of minimizing the imbalance penalty risks associated to the wind power forecast uncertainty.

\section{General Description of the Problem}

\section{A. The Virtual Power Plant Model}

In order to reduce the imbalance penalties resulting from the renewable power variability, several options can be envisaged. For example, one can aggregate geographically distributed RES sources to profit from a spatial smoothing effect of their production [10]. Alternatively, one can combine RES sources with dispatchable conventional units or energy storage device. Such options aim to increase the controllability and predictability of the overall generation mix. A prerequisite is that the market rules permit such joint participation. The combined plant is defined as a Virtual Power Plants (VPP) in [11]. Commercial VPPs consist in aggregating different distributed generation units in order to participate in the market as single entity and thus facilitate trading in electricity markets. 


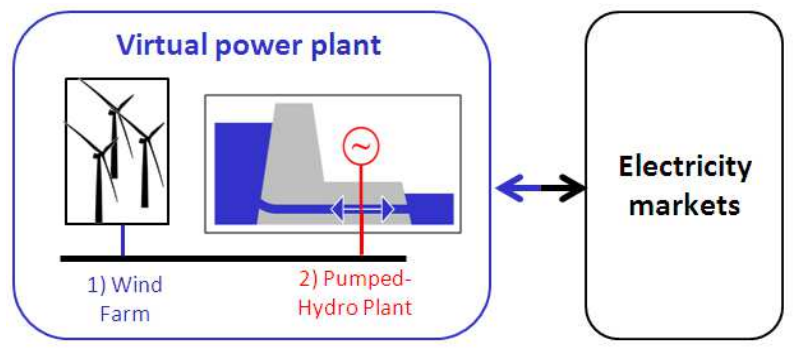

Fig. 1. Commercial VPP composed of a combination of a wind farm and a pumped-hydro plant

They can experience economies of scale in market participation and benefit from intelligent bidding to maximize revenue opportunities. The same concept is described in [12], where the authors develop a market interface for distributed generation units to formalize their participation in the wholesale market as an equivalent power producer. The VPP considered in the present study is a commercial one and consists of a combination of a pumped-hydro station with a wind farm, as described in Figure 1.

\section{B. Main Hypotheses about the Considered Market Participa- tion}

1) Energy producer: The priority in the management and operation of the storage is given to the reduction of energy imbalances. As a consequence, the energy storage device is not used for buying energy in periods where the market price is considered to be low enough, for selling it back in periods where the market price is estimated to be sufficiently high. Such a possibility has already been considered by the authors in [9], where its advantages were discussed.

Consequently, in the present study, the VPP operator is considered to be only an energy producer, and not an energy consumer. In other words, the VPP operator is not able to buy energy from the market for charging the storage device. The storage is solely charged by the wind farm production when produced wind energy exceeds contracted energy.

2) Day-ahead market: Electricity markets are usually complex due the amount of energy trading possibilities they offer, to their rules, and to the way they operate, which is usually market-specific. In this work the virtual power plant is supposed to participate only in the day-ahead market.

3) Price taker player: In our work, the electricity market is considered to be competitive and composed of a relatively high number of market participants. In addition, the total capacity of the virtual power plant is considered to be small enough so that its owner does not possess sufficient market power. In such a case, in the electricity market context, the VPP is considered to be a price taker. As a consequence, the quantityprice bid is reduced to a quantity bid, at zero price. The bid is thus always accepted, and the market price is defined by the other participants.

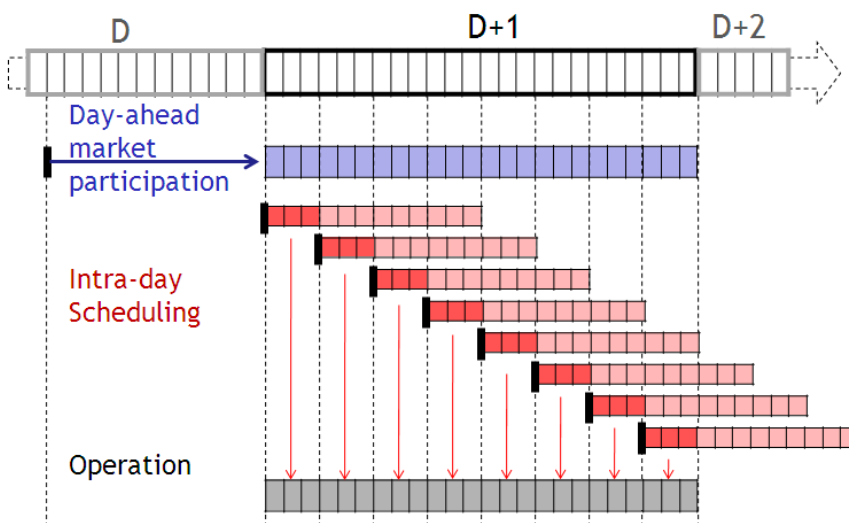

Fig. 2. Coordination of the Market participation, Intra-day Scheduling and Operation of the VPP. The vertical black lines indicate the instants when decisions are made.

4) Balance responsible entity: The VPP is assumed to be balance-responsible. The VPP is thus liable to pay penalties for the energy imbalances it generates according to the market rules. In that present study, an energy imbalance is defined as the difference between the energy delivered by the VPP and the energy contracted in the day-ahead market.

\section{Intra-day Scheduling and Operation of the VPP}

The definition of the bid or contract for the day-ahead market participation is the first decision that the VPP operator has to make under the hypotheses presented in section II-B. In order to sell energy for the next day $(D+1)$, the VPP operator proposes its quantity bid before the gate closure time during the present day $(D)$. Such bid is based on available wind power forecasts. The first blue line in Figure 2 illustrates the day-ahead bidding with a gate closure time at 12:00 PM. The quantity bid is considered to be always accepted, as stated in section II-B3, and constitutes the energy contract. Energy imbalance between the contracted energy and the delivered energy is often penalized, as explained in section II-B4. In this section, we propose a decision-making method for scheduling the energy storage device during the period of time corresponding to the day-ahead market contract, in order to minimize the imbalance penalty risks associated to wind power forecast uncertainty.

During the operation stage, the limited capacity of the device implies that the possibility to store or to deliver energy depends on the state-of-charge (SOC) level of the device. The SOC level depends on the past operation of the device. In other words, the operation of the storage device at a time $t_{i}$ depends on the operations performed prior to $t_{i}$. The temporal dependence of the storage operation leads to the need of an anticipation of the management of the storage device. For example, if the VPP operator wants to avoid extreme energy imbalances, the intra-day storage management will permit to adapt the SOC level so that the storage device has the ability to store or inject power at that critical point of time. More precisely, updated wind power forecasts are used to estimate the expected imbalance between the contracted 
energy and the future delivery. As a result, the storage schedule is continuously updated for anticipating these imbalances.

This process is performed in a rolling-window scheme as shown in Figure 2. Each schedule consists of the storage output power time series covering the length of the rolling-window. The red lines in Figure 2 show examples of the followed procedure. In the graphical example, the rolling-window lasts for 12 hours and is updated every 3 hours. The length of the rolling-window is of particular importance for integrating the temporal dependence of the storage operation into the decision.

The operation of the VPP is then based on the storage schedule. More precisely, the latest available storage intraday schedule is considered as a series of storage setpoints for the operation of the VPP. Such setpoints are represented in dark red in Figure 2. The operation points are represented as the last grey line.

\section{PROBLEM Formulation}

\section{A. Day-ahead Market Model}

Each electricity market has its own rules, defining the way electricity is to be sold or purchased, how the prices are settled, and the obligations the participants are committed to. An overview of different European electricity markets is given in [13].

Most day-ahead electricity markets are auction-based, also called spot markets. In such markets, the market system price and volumes are determined for the whole market area by matching purchasing and selling curves. The obtained market system price is called spot price. For markets including different regions, regional spot market prices are derived from system prices taking into account transmission bottlenecks.

The VPP is assumed to be a price-taker, as detailed in section II-B3, and the quantity-price bid is reduced to a quantity bid, at zero price. Under such conditions, the dayahead market participation consists in proposing an energy contract for the next day $D+1$ at the gate closure time $t_{c}$ of the day $D$. The energy storage device is not considered for the day-ahead market participation, as explained in section II-C, and consequently, the energy contract $E^{C}$ is based on the wind power forecast $\hat{P}_{t_{c}+k / t_{c}}^{W F}$, available at time $t_{c}$ :

$$
E_{t}^{C}=\hat{P}_{t_{c}+k / t_{c}}^{W F} \times \Delta t
$$

where $k$ is the horizon, also called look-ahead time of the prediction; it is selected so that the prediction $\hat{P}_{t_{c}+k / t_{c}}^{W F}$ is the prediction of the variable $P_{t}^{W F}$ for the time $t=t_{c}+k$. The symbol $\Delta t$ is the market time step, also called Program Time Unit (PTU).

\section{B. Balance Settlement}

The transmission system operator (TSO) is responsible for maintaining the physical balance between production and consumption. The VPP is assumed to be a balance responsible entity that is thus paying a market imbalance price for any contribution to the global system imbalance.

The market model used in this work for representing the regulation market is similar to those used in [4], [5]. In general terms, for a given time-step $t$, the income $I_{t}$ of a VPP that participates in the market can be formulated as the combination of the income from the contracted energy $E_{t}^{C}$ at the spot price $p_{t}$, minus the cost $c_{t}$ associated to the energy imbalance $d_{t}$ :

$$
I_{t}=p_{t} \times E_{t}^{C}-c_{t}
$$

The energy imbalance $d_{t}$ is the difference between the energy $\tilde{E}_{t}$ delivered by the VPP and the contracted energy $E_{t}^{C}$. The energy delivered by the VPP is the sum of the energy delivered by the wind farm and the energy delivered by energy storage device.

$$
\begin{aligned}
d_{t} & =\tilde{E}_{t}-E_{t}^{C} \\
& =\left(\tilde{E}_{t}^{W F}+\tilde{E}_{t}^{E S D}\right)-E_{t}^{C}
\end{aligned}
$$

The imbalance cost $c_{t}$ is a function of the energy imbalance $d_{t}$. This function depends on the spot price as well as on the regulation prices for positive and negative energy imbalances. Here it is denoted as $\delta_{t}: c_{t}=\delta_{t}\left(d_{t}\right)$. The determination of the regulation prices varies according to the considered market. In general such price are time dependent. That is why function $\delta$ is denoted as $\delta_{t}$. The imbalance cost function is generally an increasing function of the absolute energy imbalance in order to encourage market participants to have their energy contract as close as possible to their energy delivery.

\section{Intra-day Scheduling of the Virtual Power Plant}

1) Formulation of the Rolling-Window approach: This section focuses on the main contribution of the present study. Indeed, it provides the formulation of the decision-making method for scheduling the energy storage device throughout the period of time of the day-ahead market while minimizing the imbalance penalty risks associated to wind power forecast uncertainty.

The scheduling method is dynamic and based on a rollingwindow approach. In other words, the method is carried out for a period of time (window) which is then moved forward by an increment. The window width is denoted as $T_{w}$. The increment time is denoted as $T_{\text {inc }}$. Figure 2 illustrates the rolling-window approach with $T_{w}=12 \mathrm{~h}$ and $T_{i n c}=3 \mathrm{~h}$.

For a given time $t_{0}$ within the period of time of the dayahead market, the objective of the method is to determine the optimized power output of the energy storage device for the time span $\left[t_{0}, t_{0}+T_{w}\right]$. The storage power outputs are determined for every time step $\Delta t$ and are denoted as $P_{t}^{E S D, *}$. In the following equations, $t_{i}$ denotes a given time within the window and is defined as $t_{i}=t_{0}+i \times \Delta t, i \in[1, n]$. The window width $T_{w}$ is a multiple of the time step : $T_{w}=n \times \Delta t$.

At a given time $t_{i}$ within the window, the estimated imbalance $\hat{d}_{t_{i}}$ is obtained from Equation 3 by taking into account the updated forecasts $\hat{P}_{t_{i}}^{W F}$ instead of $\tilde{P}_{t_{i}}^{W F}$.

$$
\hat{d}_{t_{i}}=\left(\hat{P}_{t_{i}}^{W F}+P_{t_{i}}^{E S D}\right) \times \Delta t-E_{t_{i}}^{C}
$$


Similarly, the imbalance cost function $\delta$ is based on regulation prices that are determined after the real-time operation and, consequently, a posteriori to the given market time $t_{i}$. The decision about the storage management is thus made with an estimation of the penalization function $\hat{\delta}$. The estimated imbalance penalty $\hat{c}_{t_{i}}$ is:

$$
\hat{c}_{t_{i}}=\hat{\delta}_{t_{i}}\left(\hat{d}_{t_{i}}\right)
$$

2) Formulation of the Optimization Problem: The proposed approach is based in a decision-making method for scheduling the storage output power $P^{E S D}$ during the period $\left[t_{0}, t_{n}\right]$. For simplifying the mathematical expressions, the variable $P^{E S D}$ is renamed $u$ :

$$
P^{E S D}=u
$$

The following notation is adopted in general for every time series:

$$
\left[u_{t_{0}}, u_{t_{1}}, \ldots, u_{t_{i}}, \ldots, u_{t_{n}}\right]=[u]_{t=t_{0}}^{t_{n}}
$$

For a given time $t_{i}$, the day-ahead contract energy $E_{t_{i}}^{C}$ is already determined the day before at the gate closure time and the wind power production is estimated by $\hat{P}_{t_{i}}^{W F}$. Consequently, the estimated imbalance $\hat{d}_{t_{i}}$ given in Equation 4 is only a function of the storage output power $u_{t_{i}}$. The estimated imbalance penalty can thus be rewritten from Equation 5 as a function of the storage output power $u_{t_{i}}$ :

$$
\hat{c}_{t_{i}}=\hat{\delta}_{t_{i}}\left(\hat{d}_{t_{i}}\left(u_{t_{i}}\right)\right)
$$

The market rule model described by Equation 2 indicates that the imbalance penalties $\delta_{t_{i}}\left(d_{t_{i}}\right)$ reduce the VPP market income. Managing the storage for reducing these imbalance penalties can then be formulated as a minimization problem, where the goal is to find the energy storage device output power $u$ that minimizes a norm $\mathcal{N}$ of the imbalance penalty throughout the period of time of the considered window:

$$
\left[u^{*}\right]_{t=t_{0}}^{t_{n}}=\underset{[u]_{t=t_{0}}^{t_{n}}}{\arg \min } \mathcal{N}\left([\hat{c}(u)]_{t=t_{0}}^{t_{n}}\right)
$$

where $\hat{c}(u)$ is formulated through Equation 5.

3) The Choice of the Optimization Norm: For a given market time $t_{i}$, the estimated imbalance penalty is a real number: $\hat{c}_{t_{i}}\left(u_{t_{i}}\right) \in \mathbb{R}$. The time series $[\hat{c}(u)]_{t=t_{0}}^{t_{n}}$ is thus a $n$-dimension vector. As a consequence, the related norm $\mathcal{N}: \mathbb{R}^{n} \rightarrow \mathbb{R}$ is a real-valued function on $\mathbb{R}^{n}$.

The choice of the norm is dependent on the VPP operator risk preference regarding imbalance penalties. If the operator focuses on the total imbalance penalty during the interval $\left[t_{0}, t_{n}\right]$, one example of norm $\mathcal{N}_{1}$ could be defined as:

$$
\mathcal{N}_{1}(\hat{C}(U))=\sum_{i=1}^{n} \hat{c}_{t_{i}}\left(u_{t_{i}}\right)
$$

Focusing on extreme values of energy imbalances could lead to another norm $\mathcal{N}_{2}$ defined by:

$$
\mathcal{N}_{2}(\hat{C}(U))=\max _{i} \hat{c}_{t_{i}}\left(u_{t_{i}}\right)
$$

These two alternative norms reflect different strategies regarding decision-making under uncertainty. The first one refers to the expected value and is called the expectancy choice in [14]. Alternatively, the second norm refers to the preference of minimizing the risk of large penalties and is denoted as robust choice in [14].

4) Technical Constraints and Temporal Dependence of the Storage Management: This paragraph formulates the temporal dependence in the schedule, which results from the limited capacity of the energy storage device. The storage output power depends both on the nominal charging and discharging rates of the device and on its actual SOC level. Such level will determine whether the storage device allows to deliver or absorb the required amount of power. Consequently, for any time $t_{i}, u_{t_{i}}$ is bounded by the storage nominal charging and discharging rates, respectively $r_{c h}^{n o m}$ and $r_{d i s}^{n o m}$. The $S O C_{t_{i}}$ is bounded by the minimum and maximum SOC levels, respectively $S O C_{\min }$ and $S O C_{\max }$. These constraints define the constraint set $\mathcal{C}$ relative to the market time $t_{i}$ :

$$
\mathcal{C}_{t_{i}}:\left\{\begin{array}{l}
r_{c h}^{\text {nom }} \leq u_{t_{i}} \leq r_{\text {dis }}^{\text {nom }} \\
S O C_{\min } \leq S O C_{t_{i}} \leq S O C_{\max }
\end{array}\right.
$$

The output power of the energy storage device is assumed to be positive when delivering power to the grid (i.e. discharging) and negative when charging. Consequently, $r_{c h}^{\text {nom }}<0$ and $r_{\text {dis }}^{\text {nom }} \geq 0$.

The $S O C_{t_{i}}$ of the energy storage device is defined as the fraction of stored energy among the nominal storage capacity of the device $C_{a p}{ }^{E S D}$. The $S O C_{t_{i}}$ at a market time $t_{i}$ depends on the previous value of $S O C_{t_{i-1}}$ and on the output power of the storage device $u_{t_{i}}$ during the period $\left[t_{i-1}, t_{i}\right]$. Charging and discharging modes are considered separately:

$$
S O C_{t_{i}}=\left\{\begin{array}{l}
S O C_{t_{i-1}}-\eta_{c h} \times \frac{u_{t_{i}} \times \Delta t}{C a p^{E S D}} \Leftarrow u_{t_{i}}<0 \\
S O C_{t_{i-1}}-\frac{1}{\eta_{d i s}} \times \frac{u_{t_{i}} \times \Delta t}{C a p^{E S D}} \Leftarrow u_{t_{i}} \geq 0
\end{array}\right.
$$

where $\eta_{d i s}$ and $\eta_{c h}$ represent, respectively, the storage device discharging and charging efficiencies. The aim of this paragraph is to formulate the $S O C$ constraints defined in Equation 12 as a constraint on the decision variable $u$. In other words, the goal is to define the $S O C_{t_{i}}$ as a function of the variable $[u]_{t=t_{0}}^{t_{n}}$. The two cases corresponding to the consideration of the storage device efficiencies lead to a nonlinearity in the recursive definition of the $S O C$ in Equation 13. This non-linearity makes the general expression of $S O C_{t_{i}}$ from $[u]_{t=t_{0}}^{t_{n}}$ quite complex.

For the present study, we consider a simplified formulation by assuming a $100 \%$ charging and discharging efficiency. Under such hypotheses, the two case definition is not necessary anymore and the $S O C$ level at time $t_{i}$ can be recursively 
defined as:

$$
S O C_{t_{i}}=S O C_{t_{0}}-\sum_{k=0}^{i} \frac{u_{t_{k}} \times \Delta t}{C a p^{E S D}}
$$

The energy storage schedule is determined at a given time $t_{0}$ for the period $T_{w}$. The $S O C$ is known at the time $t_{0}$ and will be determined as the integration of the $u$ variable for the further time steps. Consequently, the storage SOC level limitation defined in Equation 12 can be written as:

$$
\left\{\begin{array}{l}
\sum_{k=1}^{i} u_{t_{k}} \leq \bar{b}=\left(S O C_{t_{0}}-S O C_{\min }\right) \times \operatorname{Cap}^{E S D} / \Delta t \\
\sum_{k=1}^{i} u_{t_{k}} \geq \underline{b}=\left(S O C_{t_{0}}-S O C_{\max }\right) \times \operatorname{Cap}^{E S D} / \Delta t
\end{array}\right.
$$

with $i=1 \ldots n$. Therefore, considering Equation 7, the constraints can be formulated as linear constraints on the vector $U=[u]_{t=t_{0}}^{t_{n}}$ as follows:

$$
\mathcal{C}^{\prime}:\left\{\begin{array}{l}
r_{c h}^{n o m} \cdot \mathbb{1} \leq U \leq r_{\text {dis }}^{\text {nom }} \cdot \mathbb{1} \\
\mathbf{A} \cdot U \leq \bar{b} \cdot \mathbb{1} \\
\mathbf{A} \cdot U \geq \underline{b} \cdot \mathbb{1}
\end{array}\right.
$$

where $\underline{b}$ and $\bar{b}$ are derived from Equation 15 . $\mathbb{1}$ is a $n \times 1$ vector and $\mathbf{A}$ is a $n \times n$ matrix defined by:

$$
\mathbf{A}=\left[\begin{array}{ccccc}
1 & 0 & 0 & \ldots & 0 \\
1 & 1 & 0 & \ldots & 0 \\
\vdots & \vdots & \vdots & \vdots & \vdots \\
1 & 1 & 1 & \ldots & 1
\end{array}\right], \mathbb{1}=\left[\begin{array}{c}
1 \\
1 \\
\vdots \\
1
\end{array}\right]
$$

The simplified decision-making problem can thus be formulated as the following linear optimization problem:

$$
\begin{array}{r}
U^{*}=\underset{U}{\arg \min } \mathcal{N}(\hat{C}(U)) \\
\text { subject to } \mathcal{C}^{\prime}
\end{array}
$$

with

$$
\hat{C}(U)=[\hat{c}(u)]_{t=t_{0}}^{t_{n}}
$$

\section{Real Time Operation of the VPP}

This section formulates a real-time operation model of the VPP. At operation time $t_{o p}$, the energy delivered by the VPP $\tilde{E}_{t_{o p}}$ is the sum of the energy $\tilde{E}_{t_{o p}}^{W F}$ delivered by the wind farm and the energy $\tilde{E}_{t_{o p}}^{E S D}$ delivered by the energy storage device :

$$
\begin{aligned}
\tilde{E}_{t_{o p}} & =\tilde{E}_{t_{o p}}^{W F}+\tilde{E}_{t_{o p}}^{E S D} \\
\tilde{E}_{t_{o p}} & =\left(\tilde{P}_{t_{o p}}^{W F}+\tilde{P}_{t_{o p}}^{E S D}\right) \times \Delta t
\end{aligned}
$$

In the scope of this study, the output power of the renewable source $\tilde{P}_{t_{o p}}^{W F}$ is assumed to be non-dispatchable. The output power delivered by the storage device $\tilde{P}_{t_{o p}}^{E S D}$ is assumed to be dispatchable with respect to the technical constraints $\mathcal{C}_{t_{o p}}$ obtained by transforming Equation 12 into Equation 21.

$$
\mathcal{C}_{t_{o p}}:\left\{\begin{array}{l}
r_{d i s}^{\text {nom }} \leq P_{t_{o p}}^{E S D} \leq r_{c h}^{\text {nom }} \\
S O C_{\min } \leq S O C_{t_{o p}} \leq S O C_{\max }
\end{array}\right.
$$

For the real-time operation of the VPP, the variable values for the previous time steps are known. More precisely, the $S O C$ level at time step $t_{o p}-\Delta t$ is known, and the $S O C$ level at $t_{o p}$ only depends on the energy storage output $P_{t_{o p}}^{E S D}$ :

$$
S O C_{t_{o p}}=S O C_{t_{o p}-\Delta t}+P_{t_{o p}}^{E S D} \times \Delta t / \operatorname{Cap}^{E S D}
$$

The technical constraints of the device at $t_{o p}$ can be rewritten by combining Equation 21 and Equation 22:

$$
\mathcal{C}_{t_{o p}}:\left\{\begin{array}{l}
r_{d i s}^{n o m} \leq P_{t_{o p}}^{E S D} \leq r_{c h}^{n o m} \\
P_{t_{o p}}^{E S D} \geq\left(S O C_{\text {min }}-S O C_{t_{o p}-\Delta t}\right) \times \frac{C a p^{E S D}}{\Delta t} \\
P_{t_{o p}}^{E S D} \leq\left(S O C_{\text {max }}-S O C_{t_{o p}-\Delta t}\right) \times \frac{C a p^{E S D}}{\Delta t}
\end{array}\right.
$$

The operation model distinguishes two cases:

1) Reference Operation: The reference case is the case without strategic intra-day storage schedule. The reference approach does not take into account any estimation of regulation price. It is based on the analysis that the imbalance penalties are generally increasing functions of the absolute value of the energy imbalance, as explained in section III-B. Consequently, reducing the absolute energy imbalance reduces the imbalance penalty. The operation of the energy storage device $\tilde{P}_{t_{o p}}^{E S D}$ is thus based on the real-time minimization of the energy imbalance between the contracted energy in the day-ahead market $E_{t_{o p}}^{C}$ and the energy delivered by the VPP $\tilde{E}_{t_{o p}}$.

$$
\begin{array}{r}
\tilde{P}_{t_{o p}}^{E S D}=\underset{P^{E S D}}{\arg \min }\left|d_{t_{o p}}\left(P^{E S D}\right)\right| \\
\tilde{P}_{t_{o p}}^{E S D}=\underset{P^{E S D}}{\arg \min }\left|\left(\tilde{P}_{t_{o p}}^{W F}+P^{E S D}-E_{t_{o p}}^{C}\right) \times \Delta t\right| \\
\text { subject to Equation } 23
\end{array}
$$

2) Strategic Operation: The strategic coordination of the wind farm and the energy storage considers the latest available storage intra-day schedule $P_{t_{o p}}^{E S, *}$ derived in Equation 17 as a series of setpoints for the storage device, while respecting the technical constraints.

$$
\begin{array}{r}
\tilde{P}_{t}^{E S D}=\underset{P^{E S D}}{\arg \min }\left|P^{E S D}-P_{t_{o p}}^{E S D, *}\right| \\
\text { subject to Equation } 23
\end{array}
$$

\section{CAse Study}

The advanced storage management strategy was applied in a real case study described below in detail. Various simulation runs are presented and analyzed in order to evaluate the benefits from the strategic storage management. The analysis focuses on the influence of the decision-making criteria on the resulting imbalance penalties.

\section{A. Overall Simulation Methodology}

1) Description of the Methodology: This section briefly presents the methodology followed for estimating the benefits related to the strategic intra-day management of the 


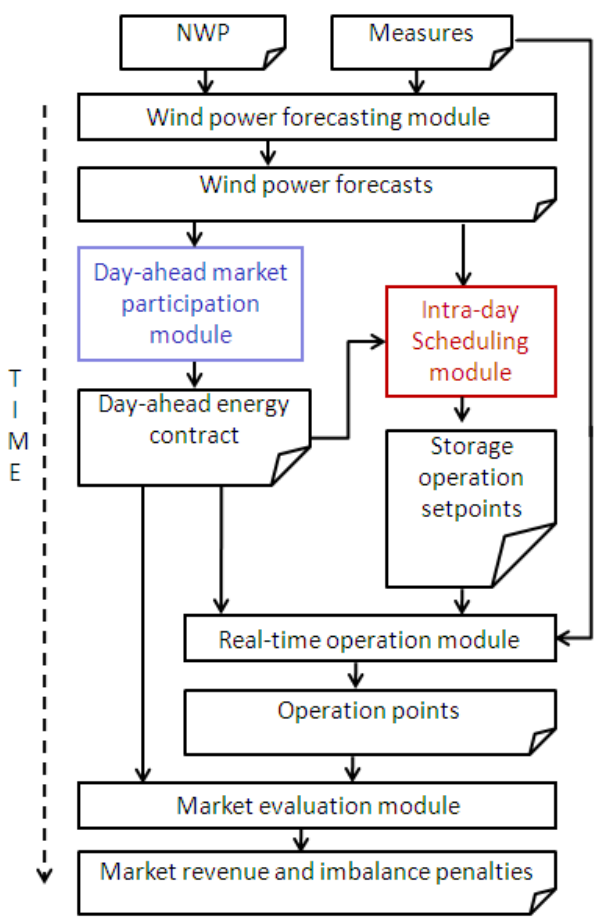

Fig. 3. Schematic representation of the overall simulation including the scheduling and the operation phases.

wind/pumped-hydro VPP, when operating under market conditions. The methodology combines the scheduling and the operation phases described in the previous section.

As shown in Figure 3, wind power measures and Numerical Weather Predictions (NWP) are used by the wind power forecasting module to produce wind power forecasts. The market evaluation consists in the quantification of the global outcome of the simulations resulting from the utilization of the proposed method. Such outcome includes the revenue, the penalties and the energy imbalances associated to the operation of the considered virtual power plant.

2) Wind Power Forecasts: Forecasts of wind power are used as input to both the day-ahead market participation and the intraday scheduling modules. In this work, such forecasts were obtained using a state-of-the-art statistical model described in [15]. It aims to model the relationship between the wind speed forecasts and the power output of the wind farm without any other considerations. This approach is often referred as power curve modeling. Here, the power curve is modeled by a piecewise least squares linear fitting of the wind-speed to power relation.

The forecasts used for the intra-day scheduling are updated forecasts, produced using as recent as possible wind power measurements as well as updated Numerical Weather Predictions (NWP). The errors of these updated forecasts are normally lower than the errors of the forecasts used for the day-ahead market participation.
3) Imbalance Penalty Forecasts: The intra-day scheduling method is based on the minimization of the estimated imbalance penalties given by Equation 5. More precisely, the imbalance cost function $\delta$ in Equation 5 is based on the difference between the spot price and the regulation price. Consequently, forecasts of both the spot and the regulation price would be necessary to perform the minimization. However, market prices are highly variable and hardly predictable as they may exhibit a feature of spikes in trajectories, as described in [16].

The present case study considers the NordPool market, where market participants are only penalized for their imbalances if these are opposite to the regulation measure taken by the TSO. The interested reader may refer to [17] for obtaining further information on NordPool market rules. The imbalance cost function $\delta_{t}$ can be formulated as:

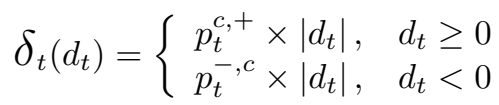

where $p_{t}^{c,+}, p_{t}^{-, c} \geq 0$ are defined by:

$$
\begin{aligned}
& p_{t}^{c,+}=p_{t}^{c}-p_{t}^{+} \\
& p_{t}^{-, c}=p_{t}^{-}-p_{t}^{c}
\end{aligned}
$$

with $p_{t}^{c}, p_{t}^{+}$and $p_{t}^{-}$being the market spot price and the regulation prices for positive and negative energy imbalances, respectively.

The estimation of the imbalance cost function $\hat{\delta}$ is modeled in the present study by the absolute function:

$$
\hat{\delta}_{t}\left(d_{t}\right)=\left|d_{t}\right|
$$

for any energy imbalance $d_{t}$. Advanced imbalance cost function models require market price forecasting (e.g. [18]).

\section{B. Description of the Case Study}

In this study, the considered VPP is composed of a 18 MW wind farm located in the North West of Denmark and a pumped-hydro station with a nominal capacity of $40 \mathrm{MWh}$, a nominal charging rate $r_{c h}^{n o m}$ of $-6 M W h / h$ and a nominal discharging rate $r_{\text {dis }}^{n o m}$ of $6 M W h / h$. We have considered the case where this VPP participates in the NordPool electricity market for the whole month of April 2002 [17].

To produce the wind power forecasts, Hirlam Numerical Weather Predictions were used as well as measured wind power from the years 2000 and 2001 as learning and testing sets, respectively. Wind power forecasts have been derived from Numerical Weather Predictions every $6 h$ of the month of April 2002.

In NordPool, the contracts for the coming day are traded on the day-ahead market, named Elspot. The Elspot gate closure time is at 12:00 pm (local time) of the preceding day. Hence, we used the last available wind power forecasts (11:00 am of the same day) as input to day-ahead market participation module. Forecast horizons were selected in order to get the forecasts for the next day. The intra-day storage scheduling is carried out every hour from updated wind power forecasts. The rolling-window width $T_{w}$ and the increment time $T_{i n c}$ 
defined in section III-C1 are chosen to be $T_{w}=12 \mathrm{~h}$ and $T_{i n c}=1 h$.

Two optimization norms related to two different decisionmaking strategies are proposed in section III-C3. These two different strategies have been simulated in order to evaluate the benefits of the proposed methodology. Both of these strategies are compared to the reference case where no intra-day storage scheduling is used, as described in section III-D. The strategies related to the norms $\mathcal{N}_{1}$ and $\mathcal{N}_{2}$ are denoted as $N_{1}$ and $N_{2}$ respectively. Similarly, the reference case is denoted by $N_{0}$.

\section{Results and Discussion}
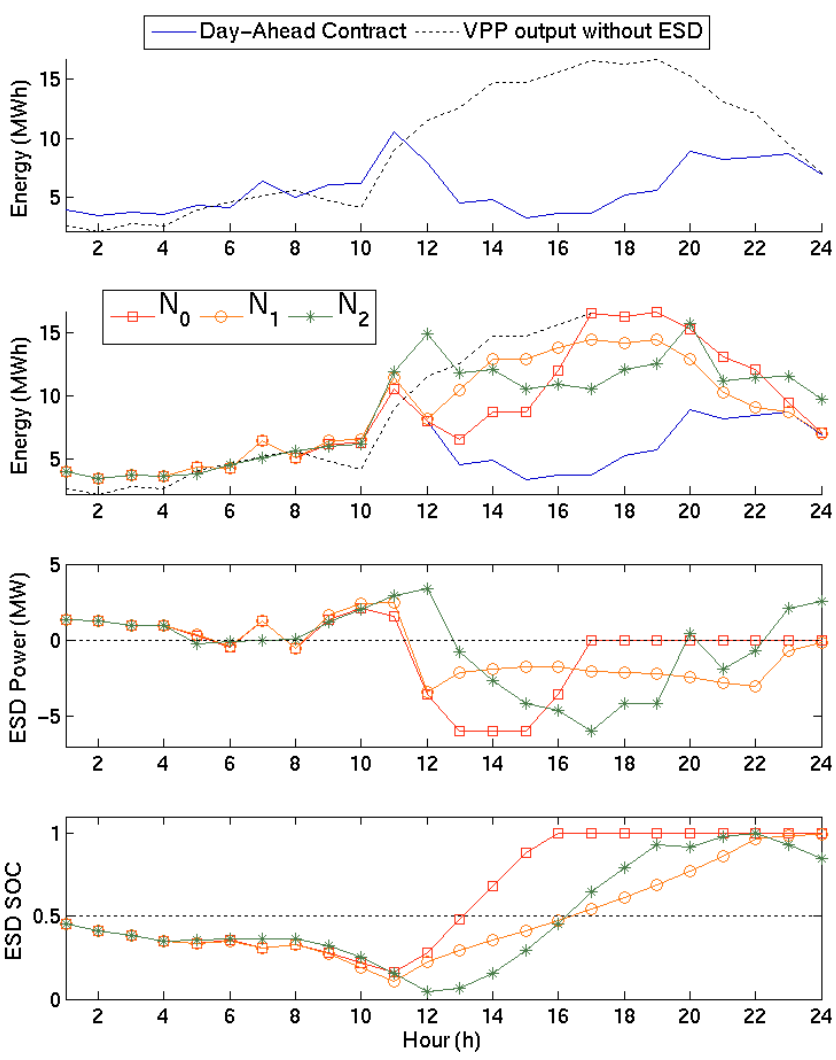

Fig. 4. Operation of the VPP, the 04/04/2004.

Figure 4 describes the operation of the virtual power plant during the 24 hours of the $4^{\text {th }}$ of April 2002. On the top graph, the blue line represents the energy contract related to the dayahead market participation and the dashed black line represents the energy output of the wind farm. The area between the black line and the blue line represents the energy imbalance without considering the storage. The imbalance energy is relatively low for the first 11 hours. From hour 12 to hour 24, the wind farm output is greater than the contracted energy, which leads to positive energy imbalance for that period.

On the second graph, the red line marked with squares represents the energy output from the combined plant energy output for the reference case $N_{0}$. Similarly, the orange line marked with circles and the green line marked with stars represent the energy output from the combined plant for the strategies $N_{1}$ and $N_{2}$, respectively. The two last graphs plot the energy storage device power output and SOC level for the various cases.

The second graph shows that the combination of the storage device with the wind farm reduces the (positive) energy imbalance for the period from hour 12 to hour 24, for all the three cases.

From hour 1 to hour 11, the three cases are similar and the energy storage device delivers or stores energy so that the VPP energy output matches the day-ahead contract. However, for the period from hour 12 to hour 24, the storage device (ESD) operation depends on the strategy:

- In the reference case $N_{0}$, the surplus energy is stored till the energy storage device is completely loaded, at hour 16 . Note that, from hour 13 to hour 15 , the storage charge is limited by its nominal charging rate equal to $r_{c h}^{n o m}=-6 M W h / h$. For hours 17 to 24 , the storage device is completely loaded (the SOC level is equal to 1 ). Consequently, no more energy can be stored and the storage output power is null.

- In the $N_{1}$ case, the storage charging power remains approximately constant for the period between hour 12 and hour 22 . The storage charging power is then reduced for hour 23 and hour 24 since the energy imbalance is reduced for the same hours.

- In the $N_{2}$ case, the energy storage device is discharged at hour 12 , which leads to an energy imbalance greater than the one obtained without storage for this hour, as shown in the second graph. From hour 13 to hour 20, the second graph shows that the difference between the green line and the blue line remains approximately constant. In other words, the charging power is set so that the imbalance is kept constant and as small as possible, which is in line with the objective of this $N_{2}$ strategy. The goal of the discharge at hour 12 is to get the storage SOC level as low as possible at hour 13 in order to be able to store as much as possible energy during the period from hour 13 to hour 20 , thus reducing the maximum imbalance during the same period.

\begin{tabular}{c|c|c|c|c}
\multirow{2}{*}{} & \multicolumn{2}{|c|}{ energy imb. $|d|(M W h)$} & \multicolumn{2}{c}{ imb. costs $c(D K K)$} \\
\cline { 2 - 5 } & mean $(|d|)$ & $q^{99}(|d|)$ & mean $(c)$ & $q^{99}(c)$ \\
\hline \hline$N_{0}$ & 0.68 & 7.78 & 18.2 & 482 \\
\hline$N_{1}$ & 0.69 & 7.76 & 14.9 & 304 \\
$N_{2}$ & 0.72 & 5.22 & 16.0 & 247 \\
\hline \hline
\end{tabular}

TABLE I

ENERGY IMBALANCE OBTAINED THROUGHOUT THE SIMULATED MONTH OF OPERATION.

Table I presents results about the distribution of the hourly absolute energy imbalances $|d|$ and thet hourly imbalance costs $c$ obtained from the simulation of the combined wind/pumpedhydro plant for the month of April 2002. The results from the strategies $N_{1}$ and $N_{2}$ are compared to the reference case $N_{0}$. The mean columns give the average of the $|d|$ and $c$ for each hour of operation. The $q^{99}$ columns present the $99 \%-$ quantile of the distributions of the hourly $|d|$ and $c$. This quantity gives an estimate of extreme values. It is defined as 
the value $q^{99}(c)$ for which the number of occurrences of $c$ greater than $q^{99}(c)$ is equal to $99 \%$ of the total number of occurrences:

$$
n\left(c<q^{99}(c)\right)=99 \% \times n_{\text {tot }}
$$

Table I shows that the average of the absolute energy imbalances obtained with the $N_{1}$ strategy $(0.69 \mathrm{MWh})$ is similar to the one obtained in the reference case $(0.68 \mathrm{MWh})$. The same strategy $N_{1}$ reduces the extreme values of energy imbalance since the $q^{99}$ value is lower than the one in the reference case. Also, the $N_{1}$ strategy reduces the average imbalance costs by $18 \%$.

Strategy $N_{2}$ strongly decreases both extreme values of absolute energy imbalance (by $37 \%$ ) and extreme values of imbalance cost (by $49 \%$ ). However, this strategy slightly increases the average energy imbalance by $6 \%$. Such an increase can be observed in Figure 4 at hour 12 when the storage device output power is increased for maximizing the capacity to store energy from hour 13 to hour 20 .

Eventually, the benefits from the $N_{1}$ strategy which aimed at reducing the total imbalance penalty are confirmed in the decrease of the average imbalance cost by $18 \%$. Similarly, the benefits from the $N_{2}$ strategy which aimed at reducing the extreme values of imbalance penalties are confirmed in the decrease of the $q^{99}$ value of the imbalance costs by $49 \%$.

Such results were obtained by considering the assumption of a $100 \%$ storage device efficiency. A more realistic value for pumped-hydro station round-trip efficiency could be $75 \%$, which is in line with the one used in [7] [8]. The influence of the storage efficiency on the benefits from the $N_{1}$ and $N_{2}$ strategies should be tested in the future for confirming these results.

\section{CONCLUSiOns}

In this work, a novel method is proposed for the management of a combined wind/pumped-hydro power plant under electricity market. The method focuses on the intra-day management of the energy storage device in order to reduce the penalty risk associated to energy imbalances, for the combined power plant operator.

The method was presented in detail and applied to a realistic test case, where real-world measured data and forecast obtained by a state-of-the-art wind power forecasting model are used.

The results clearly show that a strategic coordination of the energy storage device is a way to manage energy imbalances and the penalties associated to these imbalances. The results also demonstrate the strong influence of the scheduling strategies on the risk associated to the imbalance penalties.

\section{ACKNOWLEDGMENTS}

This work was performed in the frame of the project ANEMOS.plus (contract no 038692) financed in part by the European Commission under the $6^{\text {th }}$ RTD Framework Programme. The authors would like to thank NordPool for having supplied historical data about NordPool prices. Dr Robin Girard is acknowledged for the useful discussions and remarks.

\section{REFERENCES}

[1] S. Galloway, G. Bell, G. Burt, J. McDonald, and T. Siewierski, "Managing the risk of trading wind energy in a competitive market," Generation, Transmission and Distribution, IEE Proceedings-, vol. 153, no. 1, pp. 106-114, 2006.

[2] M. Shahidehpour, H. Yamin, and Z. Li, Market Operations in Electric Power Systems - Forecasting, Scheduling and Risk Management, J. Wiley and Sons, Eds. IEEE, 2002.

[3] G. Bathurst, J. Weatherill, and G. Strbac, "Trading wind generation in short term energy markets," Power Systems, IEEE Transactions on, vol. 17, no. 3, pp. 782-789, 2002.

[4] P. Pinson, C. Chevallier, and G. Kariniotakis, "Trading wind generation from short-term probabilistic forecasts of wind power," Power Systems, IEEE Transactions on, vol. 22, no. 3, pp. 1148-1156, 2007.

[5] J. Matevosyan and L. Soder, "Minimization of imbalance cost trading wind power on the short-term power market," Power Systems, IEEE Transactions on, vol. 21, no. 3, pp. 1396-1404, Aug. 2006.

[6] F. Bourry, J. Juban, L. M. Costa, and G. Kariniotakis, "Advanced strategies for wind power trading in short-term electricity markets," in European Wind Energy Conference, 2008.

[7] G. N. Bathurst and G. Strbac, "Value of combining energy storage and wind in short-term energy and balancing markets," Electric Power Systems Research, vol. 67, no. 1, pp. 1-8, Oct. 2003.

[8] J. Castronuovo, E.D.; Lopes, "On the optimization of the daily operation of a wind-hydro power plant," Power Systems, IEEE Transactions on, vol. 19 , no. 3 , pp. $1599-1606,2004$

[9] L. M. Costa, F. Bourry, J. Juban, and G. N. Kariniotakis, "Management of energy storage coordinated with wind power under electricity market conditions," in Probabilistic Methods Applied to Power Systems, Rincon, Puerto Rico, 2008.

[10] U. Focken, M. Lange, K. Mnnich, H.-P. Waldl, H. G. Beyer, and A. Luig, "Short-term prediction of the aggregated power output of wind farms-a statistical analysis of the reduction of the prediction error by spatial smoothing effects," Journal of Wind Engineering and Industrial Aerodynamics, vol. 90, no. 3, pp. 231-246, Mar. 2002

[11] D. Pudjianto, C. Ramsay, and G. Strbac, "Virtual power plant and system integration of distributed energy resources," Renewable Power Generation, IET, vol. 1, no. 1, pp. 10-16, 2007.

[12] G. Jimenez-Estevez, R. Palma-Behnke, R. Torres-Avila, and L. Vargas, "A competitive market integration model for distributed generation," Power Systems, IEEE Transactions on, vol. 22, no. 4, pp. 2161-2169, Nov. 2007.

[13] P. E. Morthorst, "Detailed investigation of electricity market rules," TradeWind, Tech. Rep., 2007.

[14] L. M. Costa, "Scheduling of power system cells integrating stochastic power generation,” Ph.D. dissertation, MINES ParisTech, 2008.

[15] N. Siebert, "Development of methods for regional wind power forecasting," Ph.D. dissertation, Ecole des Mines de Paris, 2008.

[16] H. Geman and A. Roncoroni, "Understanding the fine structure of electricity prices," Journal of Business, vol. 79, no. 3, p. 1, 2006.

[17] "Nord pool website." [Online]. Available: http://www.nordpool.com/

[18] T. Jonsson, "Forecasting of electricity prices accounting for wind power predictions," Master's thesis, Technical University of Denmark, Informatics and Mathematical Modelling, 2008.

Franck Bourry was born in Poitiers, France. He received his engineering and M.Sc. degree in Energetics from the École des Mines de Paris in 2005 $\mathrm{He}$ is currently a Ph.D. student at the Center for Energy and Processes of École des Mines de Paris. His research interests include electricity markets, decision making, power system operation and renewable energies.

Luís M. Costa was born in Porto (Portugal). He received his graduate degree in Electrical Engineering from the University of Porto (Portugal) in 2004. He then obtained his Ph.D. degree in Energy Systems at MINES ParisTech (France) in 2008. He is currently with AREVA T\&D (Systems BU) in Lyon (France). He is a member of the IEEE. His current main research interests include (among others) SmartGrids, FACTS devices, and large-scale integration of distributed energy resources.

George N. Kariniotakis was born in Athens, Greece. He received his Engineering and M.Sc. degrees from the Technical University of Crete, Greece and his Ph.D. degree from École des Mines de Paris in 1996. He is currently with the Center of Energy and Processes of École des Mines de Paris as a senior scientist and head of the Renewable Energies Group. He is a member of the IEEE. His research interests include among others renewable energies, distributed generation and artificial intelligence. 